\title{
Surgical procedure for unexpected balloon burst complication during endoscopic balloon dilatation in a patient with common bile duct stones
}

\author{
Koji Morishita $^{1^{*}(\mathbb{D})}$ and Hideaki Sasaki ${ }^{2}$
}

\begin{abstract}
Background: Endoscopic balloon dilatation (EBD) is the established treatment for common bile duct (CBD) stones. Although pancreatitis and bleeding have been reported as major complications of EBD, balloon-related complications are rarely reported in $\mathrm{EBD}$.

Case presentation: A 30-year-old woman with suspected CBD stones underwent endoscopic retrograde cholangiopancreatography (ERCP) and EBD. During EBD, the balloon of the EBD catheter suddenly burst at the biliary sphincter. We therefore performed surgical intervention: removal of the broken EBD catheter and T-tube drainage. Finally, the patient was discharged without any complications.

Conclusions: We present a case involving a burst balloon of an EBD catheter as a rare complication during EBD, as well as the surgical technique that was used to treat this complication.
\end{abstract}

Keywords: Endoscopic balloon dilatation, Common bile duct stones, Complications

\section{Background}

Endoscopic balloon dilatation (EBD) of the biliary sphincter can be a valuable adjunct therapeutic option for the removal of common bile duct (CBD) stones during endoscopic retrograde cholangiopancreatography (ERCP) in selected patients $[1,2]$. We herein report a very uncommon complication wherein the balloon of an EBD catheter burst during treatment of acute cholangitis.

\section{Case presentation}

A 30-year-old woman was transported to our hospital by ambulance due to epigastric pain. A laboratory analysis revealed the following: white blood cells, $4000 / \mathrm{mm}^{3}$; total

\footnotetext{
*Correspondence: morishita.accm@tmd.ac.jp

${ }^{1}$ Department of Acute Critical Care and Disaster Medicine, Tokyo Medical and Dental University Hospital of Medicine, 1-5-45 Yushima, Bunkyo-ku,

Tokyo 113-8510, Japan

Full list of author information is available at the end of the article
}

bilirubin, $3.0 \mathrm{mg} / \mathrm{dL}$; alkaline phosphatase, $640 \mathrm{IU} / \mathrm{L}$; GOT, $395 \mathrm{IU} / \mathrm{L} ; \mathrm{GPT}, 746 \mathrm{IU} / \mathrm{L}$; and amylase, $37 \mathrm{IU} / \mathrm{L}$. Abdominal CT demonstrated multiple gallbladder (GB) stones without inflammation of the GB; the diameter of the common bile duct (CBD) was $10 \mathrm{~mm}$. ERCP was performed under the suspicion of CBD stones. Bile duct cannulation was easily performed. Cholangiography revealed no apparent CBD stones. Although EBD is not routinely carried out in this situation, we carefully performed EBD due to the suspicion of CBD stones, and carefully taking the clinical course into consideration. Before the procedure, a dilatation balloon (Hurricane RX Rapid Exchange, Boston Scientific, MA, USA) was inflated as a precaution in order to check the condition of the balloon. The dilatation balloon was then passed over the guidewire and located at the site of the biliary sphincter. The balloon was inflated to 2 atmospheres of pressure. After the procedure, the balloon suddenly burst. We were unable to remove the EBD catheter because the balloon was 
caught at the biliary sphincter (Figs. 1, 2). A computed tomography (CT) scan showing the burst balloon located at the site of the biliary sphincter (Fig. 3). Finally, we had to perform surgical intervention to remove the EBD. We made an incision at the pylorus, and then we manually pulled the EBD catheter through this incision, as shown in Fig. 4a, b. The broken catheter was successfully removed without injuring the biliary sphincter. Cholecystectomy, CBD exploration, and then removal of the CBD stone were performed. A T-tube was inserted for drainage. Intra-operative cholangiography revealed no residual stones and no biliary sphincter abnormality (Fig. 5). The burst balloon of the EBD catheter is shown in Fig. 6. The patient was discharged without any complications after removal of the T-tube on post-operative day 14 .

\section{Discussion}

EBD is the treatment of choice for patients with CBD stones. The high success rate and safety of this modality have been well established by a number of studies [1-3]. Complications of EBD, such as pancreatitis, hemorrhage, perforation, and infection have been reported [4-9]. In the current case, we demonstrated balloon burst of an EBD catheter as a rare complication of EBD. According to the product information of the EBD catheter, the balloon is made from nylon [10]. We checked the condition of balloon as a precaution; however, we could not prevent this serious complication. Although no structural abnormalities of the distal bile duct were observed in this

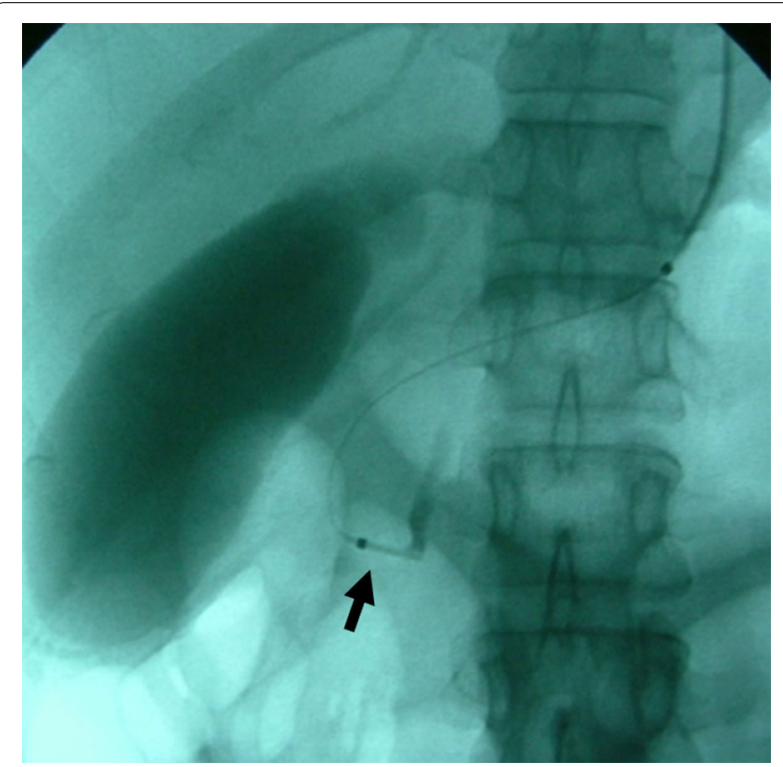

Fig. 1 Cholangiography during endoscopic balloon dilatation (EBD). The burst balloon of the endoscopic balloon dilatation (EBD) at the site of the biliary sphincter. Arrow indicates the burst balloon of the EBD catheter at the site of the biliary sphincter

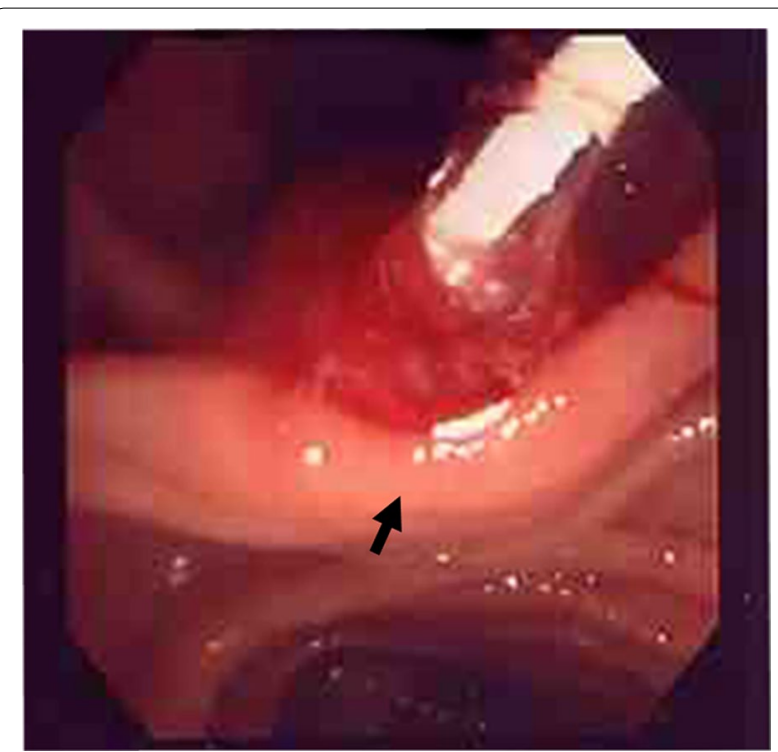

Fig. 2 Endoscopic findings during endoscopic balloon dilatation (EBD). The burst balloon of the endoscopic balloon dilatation (EBD) at the site of the biliary sphincter. Arrow indicates the burst balloon of the EBD catheter at the site of the biliary sphincter

case, stricture or a tapered distal bile duct would increase the risk of balloon-related complications. To our knowledge, the present case study represents the first report regarding a burst balloon as a complication of EBD which required surgical treatment. Through our experience, we think that it is important to provide patients with information about this complication before performing EBD. We therefore believe that we should include the information about this complication when obtaining informed consent from patients.

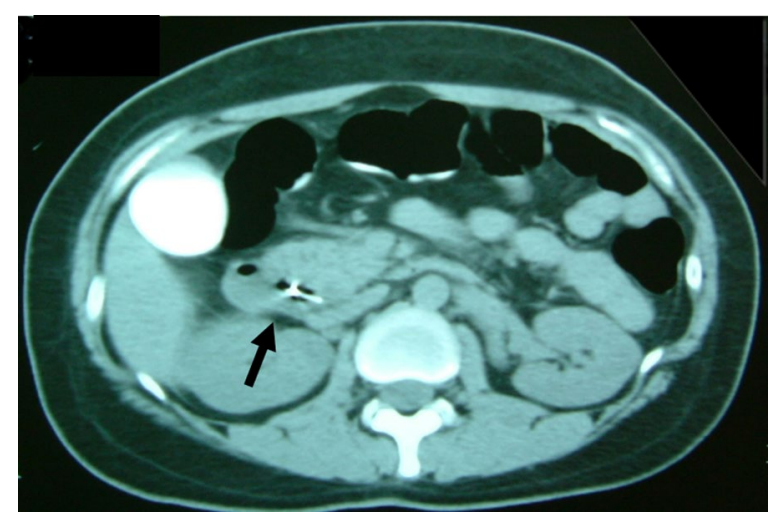

Fig. 3 Abdominal CT. A computed tomography (CT) scan showing the burst balloon located at the site of the biliary sphincter. The arrow indicates the burst balloon of the EBD catheter at the site of the biliary sphincter 


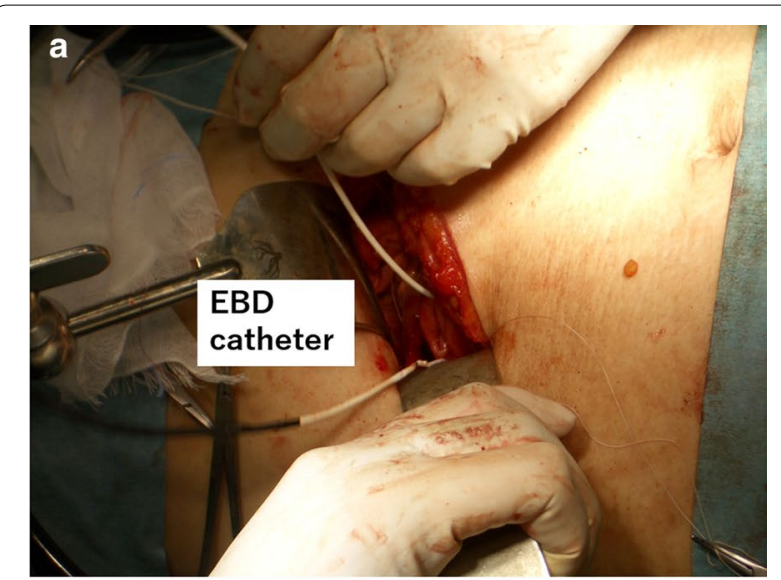

b Liver

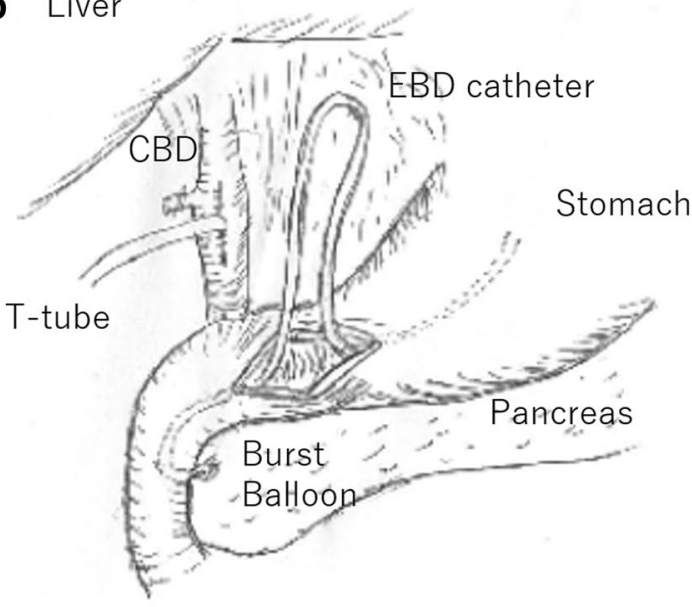

Fig. 4 a, b The surgical findings. The burst balloon of the EBD catheter was removed during the surgical procedure. An incision at the pylorus was made to remove the EBD catheter through the incision

Regarding the surgical technique, we think that there were three important considerations in the surgical removal of the burst balloon of the EBD catheter that was trapped at the biliary sphincter. First, we made the incision at the pylorus to remove the catheter, based on the consideration that an incision at the 2nd portion of the duodenum would increase the risk of postoperative complications (e.g., duodenal stenosis or leakage). Second, we preformed cholecystectomy and intra-operative cholangiography because residual stones were present in the CBD. Third, we had to pay attention to biliary sphincter edema and dysfunction induced by the burst balloon. Thus, a T-tube was inserted into the CBD after CBD stone removal.

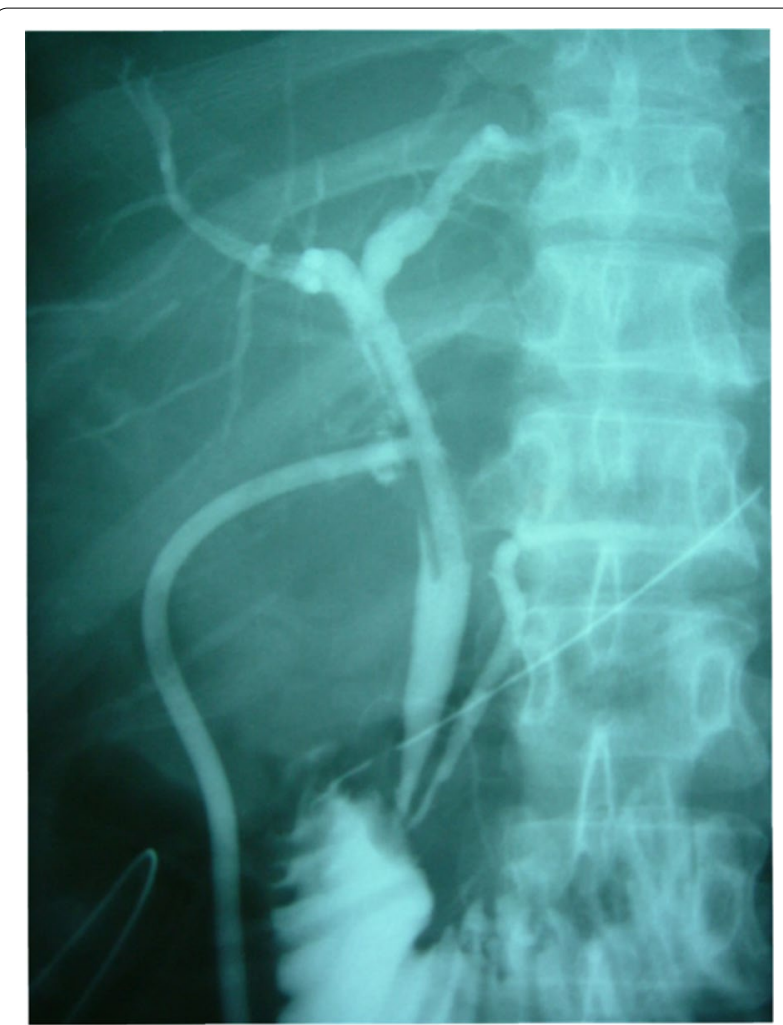

Fig. 5 Intra-operative cholangiography. Intra-operative cholangiography revealed no residual stones or abnormalities of the biliary sphincter

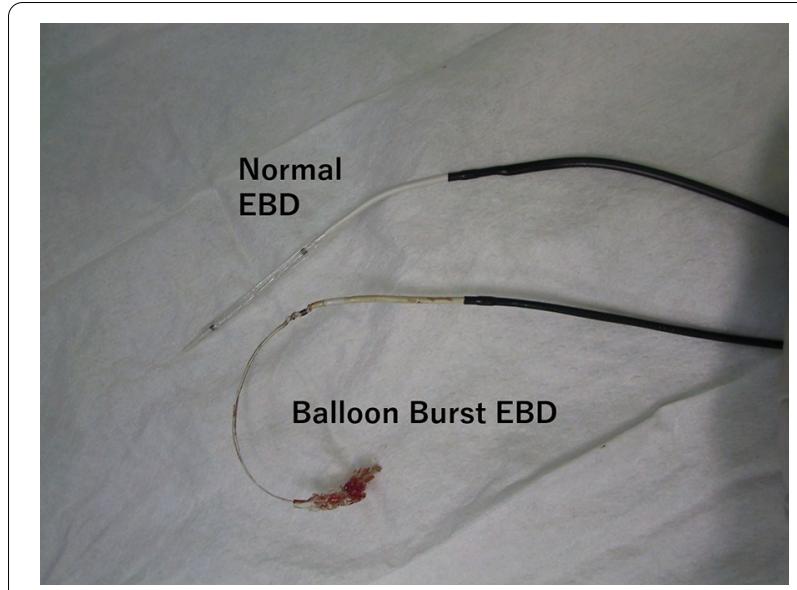

Fig. 6 The burst balloon of the EBD catheter. The burst balloon of the EBD catheter is shown in comparison to a normal balloon of an EBD catheter

\section{Conclusion}

Reports of balloon-related complications occurring during EBD are very rare. It is important to know about this serious complication and the surgical technique for that was used to treat it. 


\section{Abbreviations}

CBD: Common bile duct stones; ERCP: Endoscopic retrograde cholangiopancreatography; EBD: Endoscopic balloon dilatation.

\section{Acknowledgements}

None.

\section{Authors' contributions}

KM performed data collection and drafted the manuscript. HS participated in technical editing of the manuscript. Both authors read and approved the final manuscript.

\section{Funding}

No funding was received for this case report.

\section{Availability of data and materials}

The authors declare that all the data in this article are available within the article.

\section{Ethics approval and consent to participate}

Not applicable.

\section{Consent for publication}

The patient provided both verbal and written informed consent to publish the case, including the publication of images.

\section{Competing interests}

The authors have no conflict of interest to declare.

\section{Author details}

${ }^{1}$ Department of Acute Critical Care and Disaster Medicine, Tokyo Medical and Dental University Hospital of Medicine, 1-5-45 Yushima, Bunkyo-ku, Tokyo 113-8510, Japan. ${ }^{2}$ Department of Emergency Medicine, Okinawa Red Cross Hospital, Okinawa, Japan.

Received: 23 July 2020 Accepted: 21 September 2020

Published online: 02 October 2020
References

1. Staritz M, Ewe K, Büschenfelde KH. Endoscopic papillary dilatation, a possible alternative to endoscopic papillotomy. Lancet. 1982;1:1306-7.

2. Ortiz R, Parente A, Perez-Egido L, Burgos L, Angulo JM. Long-term outcomes in primary obstructive megaureter treated by endoscopic balloon dilation. Experience After 100 Cases. Front Pediatr. 2018;6:275.

3. Lai KH, Chan HH, Tsai TJ, Cheng JS, Hsu PI. Reappraisal of endoscopic papillary balloon dilation for the management of common bile duct stones. World J Gastrointest Endosc. 2015:7(2):77-86.

4. Vlavianos P, Chapra K, Manadalia S, Anderson M, et al. Endoscopic balloon dilatation versus endoscopic sphincterotomy for the removal of bile duct stones: a prospective randomised trial. Gut. 2003;52:1165-9.

5. Arnold JC, Benz C, Martin WR, et al. Endoscopic Papillary Balloon Dilatation vs. Sphincterotomy for removal of common bile duct stones: a prospective randomized pilot study. Endoscopy. 2001;33(7):563-7.

6. Fujisawa T, Kagawa K, Hisatomi K, Kubota K, Nakajima A, Matsuhashi N. Is endoscopic papillary balloon dilatation really a risk factor for post-ERCP pancreatitis? World J Gastroenterol. 2016;22(26):5909-16.

7. Baron TH, Harewood GC. Endoscopic balloon dilation of the biliary sphincter compared to endoscopic biliary sphincterotomy for removal of common bile duct stones during ERCP: a meta analysis of randomized, controlled trials. Am J Gastroenterol. 2004;99(8):1455-60.

8. Park SJ, Kim JH, Hwang JC, Kim HG, Lee DH, Jeong S, et al. Factors predictive of adverse events following endoscopic papillary large balloon dilation: results from a multicenter series. Dig Dis Sci. 2013;58(4):1100-9.

9. Indications, Safety, and Warnings. Biliary Balloon Dilatation Catheter, Boston, Scientific. https://www.bostonscientific.com/content/dam/bosto nscientific/endo/portfolio-group/hurricane-rx-balloon-dilation/23770 9 dfu hurricanerx.pdf. Accessed 26 June 2020.

10. Product information, Hurricane ${ }^{\mathrm{TM}} \mathrm{RX}$ Biliary Balloon Dilatation Catheter, Boston, Scientific. https://www.bostonscientific.com/jp-JP/products/ catheter-balloon/HurricaneRX.html. Accessed 25 Aug 2020.

\section{Publisher's Note}

Springer Nature remains neutral with regard to jurisdictional claims in published maps and institutional affiliations.

\section{Submit your manuscript to a SpringerOpen ${ }^{\circ}$ journal and benefit from:}

- Convenient online submission

- Rigorous peer review

- Open access: articles freely available online

- High visibility within the field

- Retaining the copyright to your article

Submit your next manuscript at $\boldsymbol{\nabla}$ springeropen.com 